\title{
Association between mothers experience of intimate partner violence and under-five morbidity in Nigeria
}

\author{
Joy A. Osifo", Olufunmilayo I. Fawole ${ }^{2}$, Adebola A. Adejimi ${ }^{3}$, Oluwakemi A. Sigbeku ${ }^{4}$ \\ ${ }^{1}$ Department of Community Medicine, University College Hospital, Ibadan, Nigeria. \\ joy.osifo@rocketmail.com \\ ${ }^{2}$ Department of Epidemiology and Medical Statistics, Faculty of Public Health, University of Ibadan, \\ Nigeria \\ ${ }^{3}$ Department of Community Medicine, Ladoke Akintola University of Technology, Nigeria \\ ${ }^{4}$ Department of Community Medicine, University College Hospital, Ibadan, Nigeria
}

\begin{abstract}
The aim of this study was to explore association between Intimate Partner Violence (IPV) and illness in childhood. The study was a secondary data analysis of the 2008 Nigeria Demographic Health Survey (NDHS), involving use of a stratified, 2-stage cluster sampling technique to select 21, I60 women with at least one child $\leq 5$ years old. Main exposure was experience of past-year IPV prior to survey. Outcome measured were risk of fever, acute respiratory infection (ARI) and diarrhoea within the past 2 weeks. The mean ages of women and children were $29 \pm 6.8$ years and $27 \pm$ I7.I months respectively. Prevalence of past-year IPV was $72.6 \%$. Main predictors of under-five morbidity were sexual and physical IPV experience of mothers (AOR: I.632; Cl: I.4I9-I.879) and (AOR: I.I7; Cl: I.02-I.36) respectively. Interventions aimed at improving child morbidity status should target protection of mothers from physical and sexual violence perpetration by partners.
\end{abstract}

Keywords: IPV, Under-five, morbidity, Association, NDHS

\section{Introduction}

Under-five morbidity and mortality are great public health problems with deleterious effects on the health of children globally (UNICEF, 20I2). Despite the decline in child morbidity and mortality rates globally, the under-five mortality rate is still high in most African countries (Black, 2003). Although the causes of mortality of children in Africa have been identified (UNICEF, 20I2), and there has been a substantial improvement in health status in the last decade, Africa still remains a continent with high prevalence of under-5 mortality. Nigeria in particular has a high under-five mortality rate which is estimated to be 143 per 1000 live births (UNICEF, 20I0). The effect of social determinants of health on this high mortality rate remains under studied in Africa. Intimate partner violence (IPV) is assumed to be one of these social determinants which adversely affect the capacity of the mother to care for the child (Osuorah et al., 20I2).

Violence Against Women (VAW) is "any act of gender-based violence that results in, or is likely to result in, physical, sexual or mental harm or suffering to women, including threats of such acts, coercion or arbitrary deprivation of liberty, whether occurring in public or in private life" (WHO, 20I2). Violence against women - particularly intimate partner violence is a major public health problem and a violation of women's human right (WHO, 20I2). IPV refers to behaviour by an intimate partner or expartner that causes physical, sexual or psychological harm, including physical aggression, sexual coercion, and psychological abuse and controlling behaviours (WHO, 20I2). Research has shown that a large proportion of women globally endure IPV, which is a recognized public health priority (WHO, 2002). IPV constitutes $80-90 \%$ of the experience of VAW. Most cases of VAW are from intimate partners and occur in the home.

The social and economic cost of IPV is enormous and has grave impact on the family. IPV has also been associated with higher rates of infant and child mortality and morbidity such as diarrhoeal disease and malnutrition (Karamagi, 2007). Women who are victims of IPV may experience isolation, inability to work, loss of wages, lack of participation in regular activities and limited ability to care for themselves and their children (WHO, 20I2). The limited ability to care for their offspring may also be an indirect consequence of IPV. This may result from the fact that the woman is not psychologically fit to make 
timely decisions on the health and well- being of her child (Ellsberg et al., 2008). The inability of the woman to make decisions may also increase child mortality and morbidity rates. Hence, morbidity and mortality may occur because of delay in making decision to assess health care, poor access to health information and delay in taking effective action when the child is ill.

IPV is one of the psychosocial factors that influence a child's morbidity status (Campbell, 2002). It could result in childhood illness by creating psychological stress, resulting from observing IPV. The stress in turn can influence immune reactivity and increase vulnerability to illness (Friedman, 2002). IPV can also affect child health outcome from the related violence, injury, and mistreatment of children by fathers who abuse their female partners (Herrenkohl, 2008) (Christian, 1997). It can also affect child health negatively from the resultant negative physical or psychological maternal health outcomes such as stress and depression, suicidal thoughts and vulnerability/risk of infectious diseases like HIV/AIDS (Ellsberg, 2008, Sutherland, 1998, Coker, 2002, Silverman, 2008).

Despite higher levels of both IPV and childhood morbidity in most developing countries, information about the association between IPV and child morbidity/mortality is limited (Jejeebhoy, 1998, Conemi, 2003). Little is known about the effect of IPV on the survival of the offspring of victims in Africa and especially in Nigeria, as such issues remain largely outside the purview of child survival programs. Addressing IPV within such programs will help reduce preventable morbidity and mortality and would also highlight the serious and grave consequences of IPV on the health and well-being of both mothers and their children. Results obtained will be able to guide policy makers and programme implementers in the development of strategies targeted at protection of mothers from IPV by their partners.

\section{Literature Review}

IPV is a significant yet preventable public health problem that affects millions of women regardless of age, economic status, race, religion, ethnicity, sexual orientation, or educational background (ACOG, 20I2). Individuals who are subjected to IPV may have lifelong consequences, including emotional trauma, lasting physical impairment, chronic health problems, and even death. Although women of all ages may experience IPV, it is most prevalent among women of reproductive age and contributes to gynaecologic disorders, pregnancy complications, unintended pregnancy, and sexually transmitted infections, including human immunodeficiency virus (HIV) (ACOG, 20I2). IPV is a pattern of assaultive behaviour and coercive behaviour that may include physical injury, psychological abuse, sexual assault, progressive isolation, stalking, deprivation, intimidation, and reproductive coercion (WHO, 20I2). These types of behaviour are perpetrated by someone who is, was, or wishes to be involved in an intimate or dating relationship with an adult or adolescent, and is aimed at establishing control of one partner over the other (WHO, 20I2).

Obtaining accurate prevalence data is somewhat difficult because IPV is often under-reported (GarciaMoreno et al., 2006) due to the sensitive nature of the subject matter. A WHO multi-country study found that out of 24,097 women interviewed from the year 2000 to 2003 , between 15-71\% of women aged 15- 49 years reported physical and/or sexual violence by an intimate partner at some point in their lives. These forms of violence can result in physical, mental, sexual, reproductive health and other health problems, and may increase vulnerability to HIV (WHO, 20I2). The reported lifetime prevalence of physical or sexual partner violence, or both, varied from $15 \%$ to $71 \%$, with two sites having a prevalence of less than $25 \%$, seven between $25 \%$ and $50 \%$, and six between $50 \%$ and $75 \%$. Between $4 \%$ and $54 \%$ of respondents reported physical or sexual partner violence, or both, in the past year. Men who were controlling were more likely to be violent against their partners. In all but one setting, women were at far greater risk of physical or sexual violence by a partner than from violence by other people (WHO, 2004).

Individual level factors such as insecurity, low selfesteem, depression and aggressive or antisocial personality disorders are linked to partner violence, as are relationship level factors such as discord or conflict in the marital relationship (Tjaden \& Thoennes, 2000). Women are particularly vulnerable to abuse by their partners in societies where there are marked inequalities between men and women, rigid gender roles, cultural norms that support a man's right to inflict violence on his intimate partner, and weak sanctions against such behaviour $(\mathrm{WHO}$, 2002).

In a population-based survey conducted between 2000 and 2003, involving 10 countries (Bangladesh, Brazil, Ethiopia, Japan, Namibia, Peru, Republic of Tanzania, Samoa, Serbia and Montenegro) with a sample size of 24,079 women between the ages of 15 to 49 years, it was reported that secondary education, high socioeconomic status, and formal marriage offered protection from IPV, while alcohol abuse, cohabitation, young age, attitudes supportive of wife beating, having extra-marital affairs, experiencing childhood abuse, growing up with domestic violence, and experiencing or perpetrating 
other forms of violence in adulthood, increased the risk of IPV. The strength of the association was found to be greatest when both the woman and her partner had the risk factor (Abramsky et al., 20II). Violence has also been associated with poverty and high parity (Ellsberg et al., 2000). In a study conducted among South African adults, $31 \%$ of women exposed to violence were beaten during one or more pregnancies, and $33 \%$ reported that beatings were commonly accompanied by forced sex (Ellsberg, 2000). Physical violence from partners also increased the risk of the woman suffering from emotional distress, and the children of mothers who had experienced violence were more than twice as likely to suffer from learning, emotional, or behavioural problems compared with children whose mothers had never been so exposed (Ellsberg, 2000).

Despite substantial improvements during the past decade, Nigeria remains a country with high prevalence of under-5 mortality, with a mortality rate of I43 per 1000 live births (UNICEF, 20I0). Every day, Nigeria loses about 2,300 under-five year olds. This makes the country the second largest contributor to the under-five mortality rate in the world (UNICEF, 20I0). Preventable or treatable infectious diseases such as malaria, pneumonia, diarrhoea, measles and HIV/AIDS account for more than 70 per cent of the estimated one million underfive deaths in Nigeria (UNICEF, 20I0). Pattern of childhood morbidity in Nigeria include: Malaria fever, acute respiratory infection (ARI), diarrhoeal diseases, measles, HIV/AIDS and malnutrition. Another study conducted in llesa, South Western Nigeria, in a multipurpose health centre among children less than 5 years old identified fever, cough and diarrhoea as the commonest presenting complaints of children ( $77.2 \%$ of all presenting complaints), with fever being the most frequent complaint (48.8\%) (Sule, 2003).

Violence against women by their husbands is hypothesized to be related directly to the poor health of children due to exposure of children to violence, and indirectly through the incapacitation of mothers (due to lack of education and employment empowerment) and direct mistreatment and neglect of children. Specific mechanisms for these relationships include immuno-suppression resulting from stress-related trauma associated with both exposure to violence against a parent (Ellsberg et al., 2008) and direct violence, injury, and mistreatment of children from fathers who abuse their female partners (Herrenkohl, 2008), as well as depression and reduced parenting capacity among abused women (Ferri, 2007)
A study in India, conducted using data from the National Family Health Survey among women of the reproductive age group found a relationship between domestic violence and under-5 child mortality. The study, with a sample size of over 39000 children under 5 years of age reported that children whose mothers were beaten up at home by their husbands or were psychologically abused had an increased likelihood (by about 21\%) of dying before their fifth birthdays as compared to those children whose mothers had no history of abuse (Saifuddin, Koenig, \& Stephenson, 2006). A population-based household survey conducted in Uganda among 457 women (with 457 infants) found a statistically significant association between IPV and childhood morbidity. Lifetime intimate partner violence was associated with infant illness- fever, diarrhoea, cough and fast breathing (OR I.8, 95\% Cl I.2-2.8) and diarrhoea (OR 2.0, 95\% Cl I.2-3.4) (Karamagi, 2007). Studies have also shown that the children of abused mothers have lower rates of immunization and higher rates of diarrhoeal disease, and are more likely to die before the age of five years (Silverman et al., 2009).

\section{Conceptual framework for the study}

A conceptual framework adapted from Emily Rico et al was modified (fig. I) and used to hypothesize the assumed association between IPV and under-five morbidity (Rico et al., 20I0). It outlines how IPV could lead to child morbidity and how other confounding variables could possibly play a role in enhancing or reducing these associations. Pathwayl shows how IPV through maternal factors lead to under- five morbidities. The health problems include mainly the physical and the psychosocial effects. All these problems tend to reduce the exposed mother's ability to cater for herself and for the child leading to poor child attention, child malnutrition and increased morbidity. Pathway 2 shows IPV could also be related to under -five morbidities via direct effect on the child. This could occur prenatally leading to poor pregnancy outcomes like ante-partum haemorrhage, spontaneous abortion, prematurity, and still births due to combined effect of trauma on the abdomen or activity of stress hormone on the pregnancy. Postnatally, children are advertently victims of IPV either when being used as a shield or when trying to intervene out of fear. Pathway 3 features social and demographic factors (confounders) which do not cause under-five morbidity directly, but mediates the association between IPV and child morbidity. 
Fig. I Conceptual Framework of the association between IPV and under-five morbidity/mortality (Rico et al, 2010)

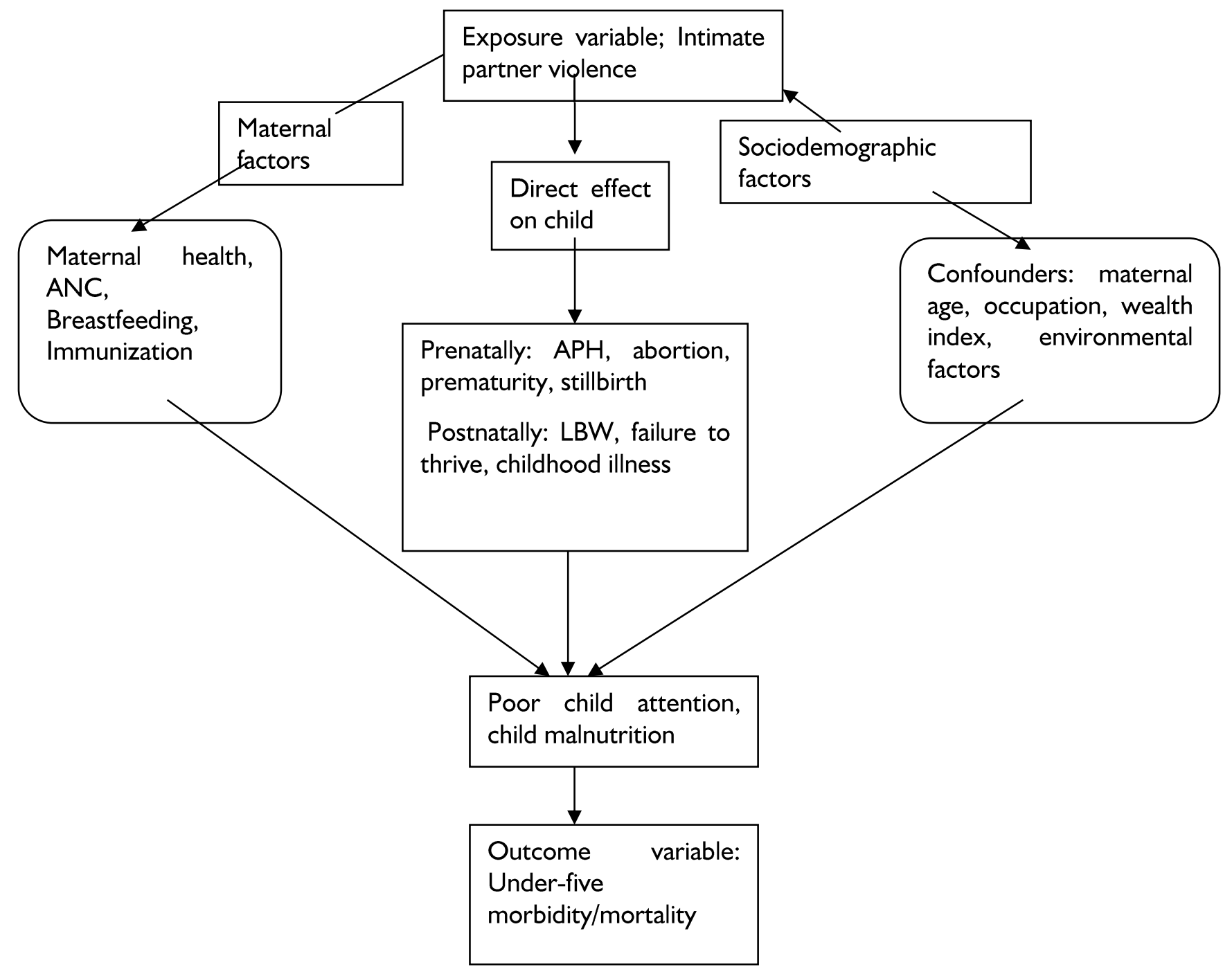

Methodology

\section{Study Area}

The 2008 NDHS was conducted in all the states of Nigeria including the Federal Capital Territory (FCT). Nigeria has 36 states (including the Federal Capital Territory) grouped into six geopolitical zones: North Central, North East, North West, South East, SouthSouth, and South West. There are 774 constitutionally recognized local government areas (LGAs) in the country and about 374 identifiable ethnic groups, with the lgbo, Hausa, and Yoruba as the major groups. The 2006 National Population Census estimates Nigeria's population to be $140,431,790$. The national growth rate is estimated at 3.2 percent per annum and population density is I50pop/sq.km. Nigeria is the most populous country in Africa (UN, 20I I).

\section{Study Design}

The study is a secondary data analysis of 2008 NDHS data. The primary survey utilized a cross sectional population based survey.

\section{Study Population}

Women aged I 5 to 49 years were the target of 2008 NDHS. For this study, married women within the reproductive age of 15-49 years in Nigeria constituted the target population. The study population was obtained as sub-samples from the women interviewed in the NDHS who participated in the domestic violence module.

\section{Eligibility Criteria:}

Inclusion criteria Married women within the reproductive age 15 to 49 years who participated in the domestic violence module and had at least one 
child $\leq 5$ years old ( $0-59$ months) were eligible for the study.

Exclusion criteria Married women aged 15 to 49 years who had not been living with her partner/spouse in the 12 months prior to survey.

\section{Sample Design}

A nationally representative sample of 36,298 households was selected for the 2008 NDHS survey. From these households, 28,647 women were eligible for interview out of which 22,36I were successfully interviewed yielding a response rate of $78.1 \%$. All the married women selected and who participated in the domestic violence module were 21,160 in number. The children were identified by matching the "caseid" numbers in the women's questionnaire, with those in the household data set, where the children's information was identified.

\section{Sampling Technique}

The sampling technique used in the primary survey was a stratified, two-stage cluster sampling technique. The primary sampling unit (PSU) also known as cluster was defined on the basis of enumeration areas.

Stage I: Eight hundred and eighty-six (886) clusters were selected and stratified into urban and rural areas based on census enumeration areas. Each cluster was divided into households from the sampling frame

Stage II: An average of 4I households was selected in each cluster by equal probability systematic sampling. All women aged 15 to 49 years were eligible for interview in each household. One eligible woman in each household was randomly selected to be asked additional questions about domestic violence

The unit of enquiry was a married woman aged between 15 to 49 years who participated in the domestic violence module, with at least one child $\leq 5$ years of age obtained from the households sampled in the $2008 \mathrm{NDHS}$.

\section{Study Variables}

\section{Independent variables}

Exposure to IPV: Exposure to IPV was assessed using the NDHS intimate partner module which is based on a modified previous version of the Conflict Tactics scale (CTS) (Straus, 1990). Based on this Scale, respondents were classified as "exposed" and "non-exposed" to violence. IPV referred to any exposure to one or several of the types of IPV; physical, sexual or psychological acts of violence against women by a current, former husband or intimate partner in the past 12 months prior to survey. Women were asked questions on physical, http://aps.journals.ac.za sexual and emotional forms of violence perpetrated by their husbands

These questions were asked to estimate the prevalence of physical, sexual, emotional violence and controlling behaviours. For women who were currently married, the questions were asked with reference to the current husband and for women who were formerly but not currently married, they were asked with reference to the women's most recent husband. Women could respond 'yes' or 'no' to each item.

Socio-demographic variables: Socio-demographic variables included age of the woman, highest level of education, region, type of residence, wealth index, occupation, partner's occupational status and educational level.

Potential Confounding variables: Some of the confounding variables included were age of child, sex of child, vaccination status, breastfeeding status, parity, use of insecticide treated bed nets, type of cooking fuel, water supply, sanitation etc.

\section{Dependent variables}

To provide an assessment of child morbidity outcomes, three common childhood illnesses were analysed: diarrhoea, acute respiratory infection (ARI) and fever. For each child under five years of age, women indicated whether the child had been ill with fever in the two weeks preceding the survey. Experience of an episode of diarrhoea ( 2 or more loose stools per day) in the 2 weeks prior to the survey was also elicited. A symptom of ARI was defined as report of cough accompanied by short, rapid breathing in the two weeks prior to the survey. Binary variables were created to define diarrhoea, ARI and fever, which indicated the presence of these outcomes among the children in the past 2 weeks.

Fever in last two weeks: In the 2008 NDHS, women were asked if their child had been ill with fever in the last two weeks preceding the survey. During the analysis, result was based on whether response was Yes/No.

Acute respiratory infection (ARI) in last two weeks: Analysis was based on Yes/No response

Diarrhoea in last two weeks: Result of analysis was based on Yes/No response

A binary variable was also created for any illness, defined as any episode of fever, cough or diarrhoea in the two weeks prior to survey

\section{Data Management}

The primary data was subjected to initial data processing, which consisted of office editing, coding of open-ended questions, data entry and editing 
computer-identified errors. SPSS version 15.0 was used for analysis of data. Frequency tables were used to show the distribution of respondents by the key variables. Values were expressed as absolute numbers, percentages and charts for key variables. The pattern and prevalence of intimate partner violence, socio-demographic and economic factors influencing victimization were described using tables. Bivariate analysis was performed for each dependent variable against the independent variables. The independent variables that were significantly associated with each dependent variable were potential confounders and were entered into a model for logistic regression. A Chi square test was used to assess association between categorical variables and level of significance was set at $5 \%$.

Logistic regression analysis was used to assess predictors of under-five morbidity. Models were also constructed to estimate odds ratio and $95 \%$ C.I for association of IPV with child morbidity (no IPV experience as referent group). Models were adjusted for a set of demographic characteristics determined a priori, specifically maternal age, educational level, wealth index and type of residence (urban vs. rural).

To account for potential environmental confounders, diarrhoea-related analyses were adjusted for sanitation status (i.e. household drinking water source and type of toilet facility). ARI-related analysis was adjusted for type of cooking fuel.

\section{Ethical Considerations}

For this study, approval to use the NDHS data was requested for from Measure DHS. In the NDHS 2008 survey, informed consent was obtained from participants, voluntariness was maintained and confidentiality was ensured. Also, it was mandatory that no harm should come to participants.

\section{Results}

Socio-demographic characteristics of respondents Table I below shows the socio demographic characteristics of respondents. The mean age of the respondents was $29.0 \pm 6.8$ years. About half of the women (5I.0\%) were between 25 and 34 years, all the women were married, many $(56.4 \%)$ were Muslims and $41.4 \%$ were Christians. Majority $(49.3 \%)$ of the respondents had no formal education and most $(72.2 \%)$ resided in rural areas. The North West geo-political zone recorded highest number of respondents $(28.3 \%)$. More than half of the respondents $(64.3 \%)$ were currently working and majority $(72.3 \%)$ had three or more children. Most respondents $(49.7 \%)$ belonged to the poor wealth category.

Table I Socio-demographic characteristics of respondents

\begin{tabular}{lll}
\hline VARIABLE & $\begin{array}{l}\text { FREQUENCY } \\
\text { N=21 I } 60\end{array}$ & $\%$ \\
\hline Age group (years) & & 25.7 \\
I5-24 & 5428 & 51.0 \\
$25-34$ & 10783 & 23.3 \\
$\geq 35$ & 4949 & \\
Maternal educational level & & 49.3 \\
No formal education & 10439 & 22.9 \\
Primary & 4839 & 22.7 \\
Secondary & 4803 & 5.1 \\
Tertiary or higher & 1079 & 17.3 \\
Region & & 21.6 \\
North Central & 3668 & 28.3 \\
North East & 4564 & 8.9 \\
North West & 5978 & 11.0 \\
South East & 1886 & 13.0 \\
South South & 2322 & \\
South West & 2742 & 27.8 \\
Type of place of residence & & 72.2 \\
Urban & 5883 & \\
Rural & 15277 & 41.1 \\
Religion & & 56.4 \\
Christian & 8692 & \\
Islam & 11937 & \\
& &
\end{tabular}




\begin{tabular}{lll} 
Traditionalist & 373 & 1.8 \\
$\begin{array}{l}\text { Others } \\
\text { Respondent currently working }\end{array}$ & 158 & 0.7 \\
Yes & 7549 & 37.5 \\
No & 13611 & 62.5 \\
Parity & & \\
1 & 2082 & 9.8 \\
2 & 3785 & 17.9 \\
$\geq 3$ & 15293 & 72.3 \\
Wealth index & & \\
Poor & 10526 & 49.7 \\
Middle & 4041 & 19.1 \\
Rich & 6593 & 31.2 \\
\hline
\end{tabular}

Child's Characteristics and morbidity pattern

Table 2 below shows the child's characteristics and morbidity pattern. Mean age of the children was 27 \pm 17.1 months. More than half $(61.9 \%)$ of the Majority of the children (86.2\%) had not slept under any bed nets within two weeks preceding the survey. Only $13.6 \%$ of them had fever, $10.3 \%$ had symptoms of ARI, and $9.0 \%$ had diarrhoea two respondents' children were over 23 months old. About half $(50.9 \%)$ were males, while $(41.1 \%)$ were females.

weeks prior to the survey. About one-fifth, $21.9 \%$ had any illness (fever, cough or diarrhoea).

Table 2 Child's characteristics and morbidity pattern

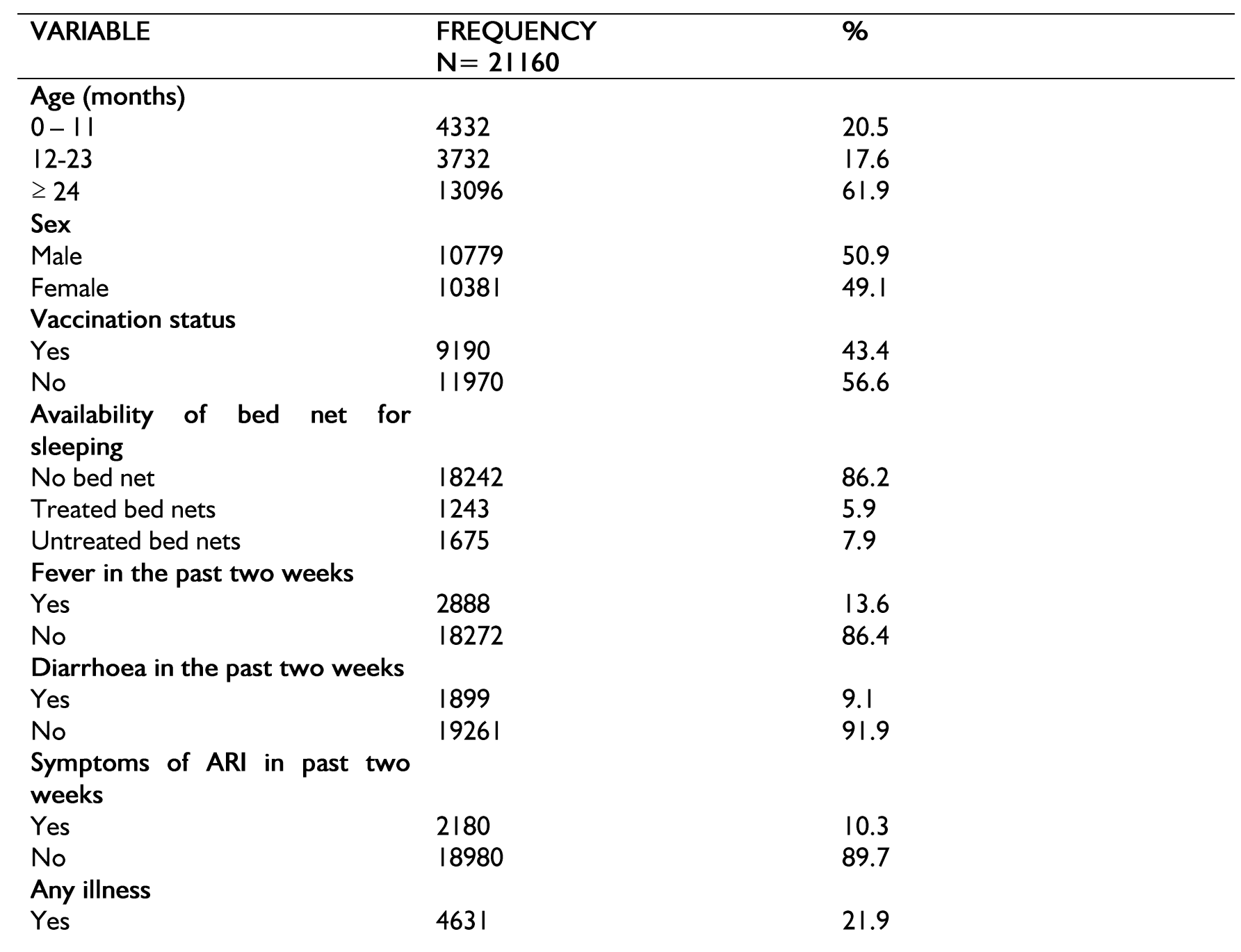


Association between socio demographic factors and childhood morbidity

Table 3 below shows the association between sociodemographic factors and childhood morbidity. From the number of respondents whose children had any illness (fever, ARI, or diarrhoea), the highest proportion was in the age category 25-34 years $(p=0.030)$. A higher proportion of respondents' children that had any illness resided in the rural areas compared to the urban $(p=0.025)$. There was more illness among the children of respondents who were currently working, compared to non-working respondents $(p=0.016)$. Parity (total number of children) was also significant $(p<0.00 \mathrm{I})$; Respondents with only one child had higher proportion of children having any form of illness. Children of respondents with secondary level of education and of the poor category of the wealth index had higher proportion of any form of illness, however these were not statistically significant $(p=0.513$ and $p=0.168$ respectively).

Table 3 Association between socio demographic factors and childhood morbidity

\begin{tabular}{|c|c|c|c|c|c|}
\hline \multirow[t]{2}{*}{ Variable } & \multicolumn{2}{|c|}{ Any childhood illness } & \multirow{2}{*}{$\begin{array}{l}\text { Total } \\
\text { n (\%) }\end{array}$} & \multirow[t]{2}{*}{$x^{2}$} & \multirow[t]{2}{*}{ p-value } \\
\hline & Yes (\%) & No (\%) & & & \\
\hline \multicolumn{6}{|c|}{ Maternal Age(years) } \\
\hline 15-24 years & $|25|(23.0)$ & $4177(77.0)$ & $5428(100)$ & 7.045 & $0.030 *$ \\
\hline $25-34$ years & 2344(50.6) & $8439(78.3)$ & $10783(100)$ & & \\
\hline$\geq 35$ years & 1036(20.9) & $3913(79.1)$ & $4949(100)$ & & \\
\hline \multicolumn{6}{|c|}{ Maternal education } \\
\hline None & $227 \mid(2 \mid .8)$ & $8168(78.2)$ & $10439(100)$ & 2.298 & 0.513 \\
\hline Primary & $1064(22.0)$ & $3775(78.0)$ & $4839(100)$ & & \\
\hline Secondary & $1076(23.2)$ & $3727(77.6)$ & $4803(100)$ & & \\
\hline Tertiary & $220(20.4)$ & $859(79.6)$ & $1079(100)$ & & \\
\hline \multicolumn{6}{|l|}{ Residence } \\
\hline Rural & $3404(22.3)$ & $11873(77.7)$ & $15277(100)$ & 5.046 & $0.025 *$ \\
\hline Urban & $1227(20.9)$ & $4656(79.1)^{\prime}$ & $5883(100)^{\prime}$ & & \\
\hline \multicolumn{6}{|c|}{ Maternal occupation } \\
\hline Working & $3048(22.4)$ & $10563(77.6)$ & $|36| \mid(\mid 00)$ & 5.760 & $0.016 *$ \\
\hline Not working & $\mid 583(2 \mid .0)$ & $5966(79.0)$ & $7549(100)^{\prime}$ & & \\
\hline \multicolumn{6}{|l|}{ Parity } \\
\hline I & $578(27.8)$ & $1504(72.2)$ & $2082(100)$ & 48.882 & $<\left.0.00\right|^{*}$ \\
\hline 2 & $770(20.3)$ & $3015(79.7)$ & $3785(100)$ & & \\
\hline$\geq 3$ & $3283(21.5)$ & $12010(78.5)$ & $15293(100)$ & & \\
\hline \multicolumn{6}{|l|}{ Wealth index } \\
\hline Poor & $2360(22.4)$ & $8166(77.6)$ & $1056(100)$ & 3.566 & 0.168 \\
\hline Middle & $858(2 \mid .2)$ & $3183(78.8)$ & $404 I(100)$ & & \\
\hline Rich & $|4| 3(2 \mid .4)$ & $5180(78.6)$ & $6593(100)$ & & \\
\hline
\end{tabular}

*Significant at $\mathrm{p}<0.05$

Table 4 below shows the association between child's characteristics and childhood morbidity. The highest proportion of children who had one or more illness (any illness) were in the 12- 23 months' age group $(p<0.001)$. Male children had one or more illness compared to the female children $(p=0.195)$. Children who were exclusively breastfed (full) had one or more illness, compared to those that that were not exclusively breastfed $(p<0.001)$. Children who had never had vaccination had one or more illness compared to those who had ever been vaccinated $(<0.00 \mathrm{I})$. A higher proportion of children who had no bed nets and those who slept under untreated bed nets had one or more illness, compared to the children that slept under treated bed nets $(p=0.054)$. 
Table 4 Association between child's characteristics and childhood morbidity

\begin{tabular}{|c|c|c|c|c|c|}
\hline \multirow[t]{2}{*}{ Variable } & \multicolumn{2}{|c|}{ Any childhood illness } & \multirow{2}{*}{$\begin{array}{l}\text { Total } \\
\text { n (\%) }\end{array}$} & \multirow[t]{2}{*}{$x^{2}$} & \multirow[t]{2}{*}{ p-value } \\
\hline & Yes (\%) & No (\%) & & & \\
\hline \multicolumn{6}{|c|}{ Age (months) } \\
\hline $0-11$ & $106 \mid(24.5)$ & $327 \mid(75.5)$ & $4332(100)$ & 408.499 & $<0.001^{*}$ \\
\hline $12-23$ & $1230(33.0)$ & $2502(67.0)$ & $3732(100)$ & & \\
\hline$\geq 24$ & $2340(17.9)$ & $10756(82.1)$ & $13096(100)$ & & \\
\hline \multicolumn{6}{|l|}{ Sex } \\
\hline Male & $2398(22.2)$ & $838 I(77.8)$ & $10779(100)$ & 1.678 & 0.195 \\
\hline Female & $2233(21.5)$ & $8148(78.5)$ & $1038 \mid(100)$ & & \\
\hline \multicolumn{6}{|c|}{ Breastfeeding status } \\
\hline Full & $1958(19.2)$ & $493 \mid(80.8)$ & $6889(100)$ & 307.722 & $<0.001 *$ \\
\hline Partial & $2673(28.4)$ & $11598(71.6)$ & $|427|(100)$ & & \\
\hline \multicolumn{6}{|c|}{ Vaccination } \\
\hline Yes & $864(19.4)$ & $349 \mid(80.6)$ & $4355(100)$ & 99.725 & $<\left.0.00\right|^{*}$ \\
\hline No & $2322(19.8)$ & $9648(80.2)$ & $11970(100)$ & & \\
\hline \multicolumn{6}{|c|}{$\begin{array}{l}\text { Availability of bed } \\
\text { net }\end{array}$} \\
\hline None & $3947(21.6)$ & 14295(78.4) & $18242(100)$ & 5.847 & 0.054 \\
\hline Treated & $280(22.5)$ & $963(77.5)$ & $1243(100)$ & & \\
\hline Untreated & $404(24.1)$ & $|27|(75.9)$ & $1675(100)$ & & \\
\hline
\end{tabular}

*Significant at $5 \%$ level of significance.

\section{Association between IPV and childhood morbidity}

Table 5 shows the association between IPV and childhood morbidity. A higher proportion of respondents who had experienced any form of IPV (combined IPV) had children with one or more illness, compared to the children of respondents who had not experienced any IPV $(p<0.001)$. A higher proportion of mothers

who had experienced physical form of IPV had a higher proportion of children with one or more illness, compared to the children of mothers with no experience of physical IPV $(p=0.009)$. Sexual IPV experience among mothers accounted for a lower proportion of children with one or more illness, compared to the non-sexual IPV experience of mothers $(p<0.001)$. A higher proportion of the children of mothers who had experienced emotional IPV recorded one or more illness, compared to the children whose mothers had not experienced any form of emotional IPV $(p<0.00 \mathrm{I})$. A larger proportion of the children of mothers who had experienced controlling behaviours from their husbands/partners had one or more illness, compared to the children whose mothers had not experienced controlling behaviours $(p<0.00 I)$

Table 5 Association between IPV and childhood morbidity

\begin{tabular}{llllll}
\hline Variable & \multicolumn{2}{c}{ Any childhood illness } & Total & $X^{2}$ & P-value \\
& Yes & No & & & \\
\hline Combined IPV & & & & \\
Yes & $1069(23.2 \%)$ & $11798(76.8 \%)$ & $15360(100 \%)$ & 55.777 & $<0.00 I^{*}$ \\
No & $3562(18.4 \%)$ & $4731(81.6 \%)$ & $5800(100 \%)$ & & \\
Physical IPV & & & & \\
Yes & $1065(23.3 \%)$ & $13022(76.7 \%)$ & $4572(100 \%)$ & 6.766 & $0.009 *$ \\
No & $3566(21.5 \%)$ & $3507(78.5 \%)$ & $16588(100 \%)$ & &
\end{tabular}




\begin{tabular}{llllll}
$\begin{array}{l}\text { Sexual IPV } \\
\text { Yes }\end{array}$ & $363(18.6 \%)$ & $1586(81.4 \%)$ & $1949(100 \%)$ & 13.351 & $<0.00 I^{*}$ \\
$\begin{array}{l}\text { No } \\
\text { Emotional IPV }\end{array}$ & $4268(22.2 \%)$ & $14943(77.8 \%)$ & $19211(100 \%)$ & & \\
$\begin{array}{l}\text { Yes } \\
\text { No }\end{array}$ & $1384(23.5 \%)$ & $4508(76.5 \%)$ & $5892(100 \%)$ & 12.287 & $<0.00 I^{*}$ \\
$\begin{array}{l}\text { Controlling } \\
\text { behaviours }\end{array}$ & $3247(21.3 \%)$ & $12021(78.7 \%)$ & $15268(100 \%)$ & & \\
Yes & & & & & \\
No & $3227(23.1 \%)$ & $10734(76.9 \%)$ & $1396 \mid(100 \%)$ & $36.24 \mid$ & $<0.00 I^{*}$ \\
\hline
\end{tabular}

Significant at $\mathrm{p}<0.05$.

Association between IPV and diarrhoea, ARI and fever

A higher proportion of mothers who had experienced combined forms of IPV had children with diarrhoea, compared to the children whose mothers had no IPV experience $(p<0.001)$. More children of mothers that experienced combined IPV whose mothers had not experienced any IPV $(p<0.00 \mathrm{I})$. Fever was highest among children of mothers with combined IPV experience, compared to mothers with no IPV experience $(p<0.00 \mathrm{I})$.

had symptoms of $A R I$, compared to the children

Table 6 Association between IPV and experienced history of fever, ARI and diarrhoea

\begin{tabular}{|c|c|c|c|c|c|}
\hline Variable & Combined IPV & & Total & $x^{2}$ & $\mathrm{p}$-value \\
\hline $\begin{array}{l}\text { Childhood } \\
\text { illness } \\
\text { Diarrhoea }\end{array}$ & Yes (\%) & No (\%) & n (\%) & & \\
\hline $\begin{array}{l}\text { Yes } \\
\text { No } \\
\text { ARI }\end{array}$ & $\begin{array}{l}1490(9.7) \\
409(7.1)\end{array}$ & $\begin{array}{l}13870(90.3) \\
539 \mid(92.9)\end{array}$ & $\begin{array}{l}15360(100) \\
5800(100)\end{array}$ & 36.160 & $<0.001$ \\
\hline $\begin{array}{l}\text { Yes } \\
\text { No }\end{array}$ & $\begin{array}{l}1702(11.1) \\
478(8.2)\end{array}$ & $\begin{array}{l}13658(88.9) \\
5322(9 \mid .8)\end{array}$ & $\begin{array}{l}15360(100) \\
5800(100)\end{array}$ & 36.730 & $<0.001$ \\
\hline
\end{tabular}

Fever

\begin{tabular}{llllll} 
Yes & $2251(14.7)$ & $13109(85.3)$ & $15360(100)$ & 48.173 & $<0.001$ \\
No & $637(11.0)$ & $5163(89.0)$ & $5800(100)$ & & \\
\hline
\end{tabular}

Predictors of child morbidity

Multivariable analysis using logistic regression revealed that the significant predictors of childhood morbidity were parity, breastfeeding status, vaccination, spousal alcoholic consumption, sexual IPV and physical IPV. Women with 3 or more children were 1.4 times more likely to have a child with any illness, compared to women with only one child (AOR: I.388; 95\% Cl: I.I88-I.507). Women who were currently working were significantly less likely to have children with any illness, compared to the children of women who were not currently working (AOR: $0.908 ; 95 \% \mathrm{Cl}$ : $0.846-0.976$ ). Mothers whose children had ever had vaccination were significantly less likely to have any illness, compared to mothers whose children had never had any vaccination (AOR: $0.689 ; 95 \% \mathrm{Cl}$ : $0.644-0.737$ ). Women whose children were exclusively breastfed were less likely to have any illness, compared to the children who were not exclusively breastfed (AOR: 0.294; 95\% Cl: 0.20I-0.430). Women whose husbands/partners consumed alcohol were 1.3 times more likely to have children with any illness, compared to the women whose husbands/partners do not consume alcohol (AOR:I.I73; 95\% Cl: I.066I.292). Children of women who had not experienced any IPV were significantly less likely to have any illness, compared to the children of women with IPV experience (AOR: $0.82 \mathrm{I} ; 95 \% \mathrm{Cl}$ : $0.70 \mathrm{I}-0.960)$. 
Table 7 Logistic regression on predictors of childhood morbidity

\begin{tabular}{|c|c|c|c|c|}
\hline VARIABLE & OR & $\begin{array}{ll}95 \% & \mathrm{Cl} \\
\text { Lower } & \\
\end{array}$ & 95\% Cl Upper & p-value \\
\hline \multicolumn{5}{|l|}{ Type of residence } \\
\hline Rural(REF) & 1.000 & & & \\
\hline Urban & 0.923 & 0.851 & 1.001 & 0.052 \\
\hline \multicolumn{5}{|l|}{ Maternal age } \\
\hline I5-24 years(REF) & 1.000 & & & \\
\hline $25-34$ years & 1.017 & 0.934 & I.107 & 0.705 \\
\hline$\geq 35$ years & 1.018 & 0.911 & 1.137 & 0.755 \\
\hline \multicolumn{5}{|c|}{ Respondent working } \\
\hline Yes & 0.908 & 0.846 & 0.976 & $0.009 *$ \\
\hline No(REF) & 1.000 & & & \\
\hline \multicolumn{5}{|l|}{ Parity } \\
\hline I (REF) & 1.000 & & & \\
\hline 2 & 0.953 & 0.864 & $1.05 \mid$ & 0.337 \\
\hline$\geq 3$ & 1.338 & 1.188 & 1.507 & $<0.00 I^{*}$ \\
\hline \multicolumn{5}{|l|}{ Vaccination } \\
\hline Yes & 0.689 & 0.644 & 0.737 & $<0.00 I^{*}$ \\
\hline No(REF) & 1.000 & & & \\
\hline \multirow{2}{*}{\multicolumn{5}{|c|}{$\begin{array}{l}\text { Exclusive } \\
\text { breastfeeding }\end{array}$}} \\
\hline & & & & \\
\hline Partial(REF) & 1.000 & & & \\
\hline Full & 0.294 & 0.201 & 0.430 & $<0.00 I^{*}$ \\
\hline \multicolumn{5}{|c|}{ Partner alcohol use } \\
\hline Yes & 1.173 & 1.066 & 1.292 & $<0.00 I^{*}$ \\
\hline No(REF) & 1.000 & & & \\
\hline \multicolumn{5}{|l|}{ Any IPV } \\
\hline Yes(REF) & 1.000 & & & \\
\hline No & 0.821 & 0.701 & 0.960 & $0.014 *$ \\
\hline
\end{tabular}

* Significant at $\mathrm{p}<0.05$

Logistic Regression on types of IPV and childhood morbidity

Multivariate analysis using logistic regression revealed that a significant predictor of childhood morbidity was sexual and physical IPV experience of mothers. Mothers who experienced sexual IPV were significantly more likely to have children with fever (AOR: I.52; 95\% Cl: I.284-I.79I), ARI (AOR: I.362; 95\% Cl: I.I43-I.624) and diarrhoeal morbidities (AOR: 1.619; 95\% Cl: 1.304-2.0I0), compared to the mothers with no experience of sexual IPV.
Maternal experience of physical IPV was also significantly associated with diarrhoeal morbidity (AOR: I.I79; 95\% Cl: 1.018-I.364). Mothers who had experienced physical IPV were more likely to have children with diarrhoeal morbidity, compared to the children of mothers with no physical IPV experience. Mothers who experienced sexual IPV were more likely to have children with any illness compared to mothers who had not experienced sexual IPV (AOR: I.632; 95\% Cl: I.4I9-I.879). 
Table 8 Logistic Regression on types of IPV and childhood morbidity

\begin{tabular}{|c|c|c|c|c|}
\hline & $\begin{array}{l}\text { Diarrhoea } \\
(95 \% \mathrm{Cl})\end{array}$ & $\begin{array}{l}\text { ARI } \\
\text { AOR }(95 \% \mathrm{Cl})\end{array}$ & $\begin{array}{l}\text { Fever } \\
\text { AOR }(95 \% \mathrm{Cl})\end{array}$ & $\begin{array}{l}\text { Any illness } \\
\text { AOR (95\% Cl) }\end{array}$ \\
\hline \multicolumn{5}{|l|}{ Types of IPV } \\
\hline $\begin{array}{l}\text { None } \\
\text { (Reference) }\end{array}$ & 1.000 & 1.000 & 1.000 & 1.000 \\
\hline Sexual & $1.62(1.30-2.01) *$ & $1.36(1.14-1.62) *$ & I.52(I.28-।.79)* & I.63(I.42-I.88) * \\
\hline Physical & $1.17(1.02-1.36) *$ & $0.65(0.58-0.75)$ & $0.84(0.78-0.94)$ & $0.85(0.77-0.94)$ \\
\hline Emotional & $0.79(0.71-0.90)$ & $0.94(0.84-1.06)$ & $0.87(0.79-0.97)$ & $0.87(0.80-0.95)$ \\
\hline $\begin{array}{l}\text { Controlling } \\
\text { behaviour }\end{array}$ & $0.7 \mid(0.64-0.79)$ & $0.82(0.74-0.90)$ & $0.79(0.73-0.87)$ & $0.8 \mathrm{I}(0.75-0.87)$ \\
\hline
\end{tabular}

*Significant at $p<0.05$

\section{Discussion}

The success of any violence prevention programme lies on the awareness of the prevalence and adverse consequences of IPV to both mother and child by members of the society. Various studies conducted have examined IPV prevalence and its effect on women's health, but very few have related it to the health of children. This study focused on women that had experienced IPV in the past year to see how IPV experience affected the health of their children. The study also explored other factors that were responsible for childhood morbidity in Nigeria which include type of residence, region, wealth index, mother's educational level and environmental factors such as drinking water source, toilet facility and type of cooking fuel used in the home.

The findings of this study revealed that approximately three-quarter $(72.6 \%)$ of currently married Nigerian women with children below the age of five years experienced combined IPV (physical, sexual, emotional and controlling behaviour) in the past year. This was in accordance with the study conducted by Sileshi et al in Ethiopia where past 12 months' prevalence of IPV was $72.5 \%$, and in contrast to the study done in Bangladesh where prevalence of maternal IPV experience was $29 \%$. A possible explanation for this seemingly disparity in prevalence from the study could be adduced to the inclusion of controlling behaviour as a type of IPV which was not included in the previous studies cited (Sileshi et al., 20I I).

A high prevalence of physical and emotional IPV experience was found among mothers of under- five children. This finding was consistent with a study done in India where $37 \%$ of women admitted to being physically or sexually abused by their husbands (Ackerson and Subramanian, 2009). Findings were also in accordance with a study conducted in South Africa where prevalence of physical violence against a current female partner was $27.5 \%$ (Gupta et al., 2008). Findings also revealed that mothers who had experienced emotional violence and controlling behaviour were more than half of the respondents. According to the NFHS conducted in India, prevalence of physical IPV was $35 \%$, sexual IPV was $10 \%$ and emotional IPV was 16\% (Asling-Monemi et al., 2008) which corresponds with findings from this study. The high prevalence of emotional IPV also corroborates findings from the work of Fawole et al. conducted in Ibadan, South Western Nigeria among rural and urban communities, where prevalence of emotional violence was found to be high. The implication of this high prevalence demonstrate the need to implement primary prevention strategies such as enacting legislation and developing policies that protect women; addressing discrimination against women and promoting gender equality by ensuring women are empowered in every facet of life.

A previous study conducted in Bangladesh showed that factors influencing childhood morbidity included young maternal age, maternal educational level, parity and maternal occupation (Silverman et al., 2009). Other studies have shown early motherhood, maternal unemployment (Goodwin et al., 2003), severe poverty (Carlson et al., 2000), and spousal alcoholic consumption (Sharps et al., 2003), as factors influencing childhood morbidity. However, in this study, predictors of child morbidity were maternal age, parity, breastfeeding, vaccination status of child and partner alcoholic consumption. Similarly, in studies done in South Africa and Ethiopia, husbands' alcohol consumption was a major predictor of childhood morbidity (Gass et al., 20I I), (Sileshi et al., 20II). Another major predictor of childhood morbidity from this study was child's vaccination status and findings was contrary to results of the Uganda study (Karamagi, 2007), where association of vaccination with infant illness was significant in the unadjusted analysis but was not significant on adjustment for logistic regression http://aps.journals.ac.za 
model. Possible explanation for the significant association found from this study could be as a result of the large sample size of the NDHS data used which increased the validity, compared to their population-based household survey with a sample size of 457 women.

Urgent need arises for women empowerment by the increased employment of women. Female empowerment will foster protection from IPV to a large extent. Education will empower the woman to seek accurate information and make informed choices concerning health care needs of her child, and also to take proactive actions when the child becomes ill. An educationally empowered woman would also be more knowledgeable on spacing of Uganda (Karamagi et al., 2007) found mixed evidence for an association between maternal lifetime IPV and common childhood illness. The current research expands on these previous studies by using a large national sample from the NDHS and included information on the association between maternal physical, sexual, emotional IPV and controlling behaviours with common childhood illness. Prevention of physical and sexual abuse of mothers by their partners is essential for the improvement of child health in Nigeria.

\section{Limitations}

Findings from this study though corroborated by other studies, had some limitations. First, it was not possible to determine temporality, whether IPV occurred before or after the childhood illness, therefore longitudinal studies may be required to ascertain causality in the association between IPV and childhood morbidity/mortality. Also, the respondents might have experienced the different types of IPV. This may be underreported because IPV is a sensitive issue, usually associated with stigmatization. Thus, women may be reluctant to reveal their true abuse status.

\section{Conclusion and Recommendations}

Findings from this study revealed that experience of physical and sexual IPV among women in Nigeria is a key determinant of under-five morbidity (diarrhoea and ARI). Most common morbidities identified were diarrhoea, ARI and fever. Sexual IPV experience of mothers was found to be a major predictor of the commonest childhood morbidities and this was significant for diarrhoea, ARI and fever. Prevalence of IPV was found to be high in Nigeria, taking into consideration all forms of IPV, including controlling behaviour

Much has been advocated and several suggestions has been made by several authors on proffering lasting solutions to curbing the menace of IPV that http://aps.journals.ac.za subsequent pregnancies and appropriate family planning methods suitable to her needs.

In Nigeria, maternal experience of sexual IPV was associated with increased risk of any illness, diarrhoea, ARI, and fever in children aged five years and younger. The findings of an increased risk of childhood diarrhoea, ARI and fever in abused women's children was in consonance with previous reports in Bangladesh (Silverman et al., 2009) of an association between physical or sexual partner violence and diarrhoea and ARI of the child. This finding is similar to results from the study by Rahman and Mostofa (2009) in Bangladesh where physical and sexual IPV experience of mothers predicted childhood diarrhoea and ARI. Another study in has become entrenched in the society. Recommendations from this study involve creation of public policies and laws that protect women from experiencing violence at local and International levels. Legislation and policies must reinforce the message that intimate partner violence is a crime and that perpetrators will be punished and victims protected. These policies must focus on the protection of children and address the impact of violence in the home on children. It is also important to enact legislation and develop policies that address discrimination against women and promote gender equality. Women should be empowered by way of education and employment as IPV has been reported to be a consequence of gender inequality. This is to enable them improve their ability in making informed choices and decisions with regards to their health and that of their children. It is also advocated that routine screening of women for IPV by health care professionals should be incorporated into basic healthcare delivery services, especially the infant welfare clinics and also, provision of counselling services for identified victims of abuse.

\section{Conflict of Interest:}

The authors declare that they have no conflict of interest.

\section{References}

Abramsky, Watts, Garcia-Moreno, Devries, Kiss, Ellsberg, Jansen \& Heise 201 I. What Factors Are Associated With Recent Intimate Partner Violence? Findings From The Who Multi-Country Study On Women's Health And Domestic Violence. BMC Public Health II.

Ackerson \& Subramanian 2009. Intimate Partner Violence And Death Among Infants And Children In India Pediatrics 124.

ACOG. (20I2). Intimate Partner Violence. American College of Obstetrics and Gynaecology. 
Asling-Monemi, K., Pena, R., Ellsberg, M. \& Persson, L. 2008. Violence Against Women Increases The Risk Of Infant And Child Mortality. A Case Referent Study In Nicaragua. WHO Bulletin, 8I, $10-18$.

Black, R. E. E. A. 2003. Why And Where Are 10 Million Children Dying Every Year? Department Of International health, John Hopkins Bloomberg School Of Public Health, Baltimore, USA 36I, 2226-34.

Campbell, J. 2002. Health Consequences Of Intimate Partner Violence. Lancet, 359, I 33 I-I 336.

Carlson, Worden, Ryn \& Bachman 2000. Violence Against Women: Synthesis Of Research For Service Providers. Final Report To The National Institute Of Justice. In: Justice, U. S. D. O. (Ed.). Washington, Dc: National Institute Of Justice.

Christian, C. W., Scribano, P., Seidl, T., \& PintoMartin, J.A. 1997. Pediatric Injury Resulting From Family Violence. Paediatrics, 99.

Coker, A. L., Davis, K.E., Arias, I., Et Al. 2002. Physical And Mental Health Effects Of Intimate Partner Violence For Men And Women. Am J Preventat Med, 23, 260e8. Am J Preventat Med, 23, 260.

Coker, A. L., Sanderson, M., Dong, B., 2004. Partner Violence During Pregnancy And Risk Of Adverse Pregnancy Outcome. Paediatric And Perinatal Epidemiology, 18, 260-269.

Conemi, K., Pena, R., Ellsberg, M.C., 2003. Violence Against Women Increases The Risk Of Infant And Child Mortality: A Case Referrent Study In Nicaragua. Bulletin World Health Organization, $81,10-16$.

Ellsberg, M., Jansen, H.A., Heise, L., Watts, C.H., \& Garcia-Moreno. C. 2008. W.H.O. Multicountry Study On Women's Health And Domestic Violence Against Women Study Team. Intimate Partner Violence And Women's Physical And Mental Health In The Who Multi-Country Study On Women's Health And Domestic Violence: An Observational Study. . Lancet, 37I, I I65-II 72.

Fawole, O. I. 20II. Prevalence Of VAW Against Pregnant Women In Ibadan. AJMMS, 39, 293-303.

Ferri, P. E. (2007). The Impact Of Maternal Experience Of Violence And Common Mental Disorders On Neonatal Outcomes: A Survey Of Adolescent Mothers In Sao Paulo, Brazil. BMC Public Health, 7, 42-7.

Friedman, E. M., David, A.L., 2002. Environmental Stress Mediates Changes In Neuroimmunological Interactions. . Toxicology Science, 67, 4-I0.

Gass, Stein, Williams \& Seedat 2011. Gender Differences In Risk For Intimate Partner Violence Among South African Adults J Interpers Violence. , 26, 2764-2789.
Goodwin, Chandler \& Meisel 2003. Violence Against Women: The Role Of Welfare Reform. Final Report To The National Institute Of Justice, 2003, Ncj 205792. . In: Justice, U. S. D. O. (Ed.). Washington, DC.

Gupta, Silverman, Hemenway, Acevedo-Garcia, Stein \& Williams 2008. Physical Violence Against Intimate Partners And Related Exposures To Violence Among South African Men. . CMAJ, I79, 535-54l.

Herrenkohl, T. I., Sousa, C., Tajima, E.A., Herrenkohl, R.C., \& Moylan, C.A. 2008. Intersection Of Child Abuse And Children's Exposure To Domestic Violence. Trauma Violence Abuse, 9, 84-99.

Jejeebhoy, S. J. 1998. Associations Between Wife Beating And Fetal And Infant Death: Impressions From A Survey In Rural India. Stud Fam Plann, 29, 300-308.

Karamagi, C. A., Tumwine, J. K., Tylleskar, T. And Heggenhougen, K. 2007. Intimate Partner Violence And Infant Morbidity: Evidence Of An Association From A Population-Based Study In Eastern Uganda In 2003. . Bmc Pediatr, 7, 7-34.

Rico, E., Fenn, B., Abramsky, T. \& Watts, C. 2010. Associations Between Maternal Experiences Of Intimate Partner Violence And Child Nutrition And Mortality: Findings From Demographic And Health Surveys In Egypt, Honduras, Kenya, Malawi And Rwanda. J Epidemiol Comm Hlth.

Saifuddin, Koenig, \& Stephenson, E. (2006). Effect Of Domestic Violence On Perinatal And Early Childhood Mortality; Evidence From North India. American Journal of Public Health, 96.

Sharps, Campbell, Gary \& Webster 2003. Risky Mix: Drinking, Drug Use, And Homicide. NIJ Journal, 250, 8-I3.

Sileshi, Mesganaw \& Alemayehu 20II. Intimate Partner Violence Against Women In Western Ethiopia: Prevalence, Patterns, And Associated Factors BMC Public Health II.

Silverman, Decker, Gupta, Kapur, Raj \& Naved 2009. Maternal Experience Of Intimate Partner Violence And Child Morbidity In Bangladesh. Arch Paediatr Adolesc Med, 163, 700-705.

Silverman, J. G., Michele, R.D., Niranjan, S., Et Al. 2008. Married Indian Women Intimate Partner Violence And Hiv Infection Among Them. Jama, 300, 703-7I0.

Straus, M. A. (Ed.) 1990. Measuring Intrafamily Conflict And Violence. The Conflict Tactic Scales., New Brunswick, New Jersey, Usa: Transaction Publishers.

Sule, S. (2003). Childhood Morbidity And Treatment Pattern at the Multipurpose Health Centre, llesa, 
Nigeria. Nigerian Journal of Medicine, 12, 145149.

Sutherland, C., Bybee, D., \& Sullivan, C. 1998. The Long Term Effects Of Battering On Women's Health. Women's Health Issues, 4, 4I-70.

Tjaden, P., \& Thoennes, N. (2000). Extent, Nature, And Consequences Of Intimate Partner Violence: Findings From The National Violence Against Women Survey. Violence against Women, 6, I42161.
UNICEF 20I0. At A Glance: Nigeria Statistics. UNICEF.

UNICEF 2012. UNICEF Article On Under-Five Mortality By Cause. Child Health Epidemiology Reference Group (CHERG).

WHO 2012. Violence Against Women: Intimate Partner And Sexual Violence Against Women. Fact Sheet No 239. 